\title{
AS POTENCIALIDADES ANALÍTICAS DA NOVA SOCIOLOGIA ECONÔMICA
}

Edmilson Lopes Júnior*

\begin{abstract}
Resumo: A Nova Sociologia Econômica é a mais promissora reação dentro do campo da Sociologia à investida do "imperialismo disciplinar" da Economia, ocorrida na década de 80. Neste artigo, busca-se traçar um panorama desse rico campo da investigação sociológica contemporânea.

Palavras-chaves: Teoria sociológica, Sociologia Econômica, instituições, mercados.
\end{abstract}

A Nova Sociologia Econômica tem sido uma das mais promissoras reações produzidas dentro do campo da Sociologia à investida do "imperialismo disciplinar" da Economia, ocorrida na década de 80. Nesse momento, quando o reaganismo e o thatcherismo dominavam as paisagens políticas dos EUA e Inglaterra, o paradigma neoclássico hegemônico na Economia parecia, enfim, ter conquistado legitimidade suficiente para ultrapassar o campo limitado das predições sobre o mercado e arvorar-se possuidor de uma base epistemológica capaz de produzir explicações convincentes sobre temas até então abordados prioritariamente pelos sociólogos. Foi assim que os economistas passaram a abordar questões como as escolhas no casamento, as redefinições das taxas de natalidade ou a produção de movimentos sociais em determinados setores da vida social.

\footnotetext{
Professor do Departamento de Ciências Sociais, da Universidade Federal do Rio Grande do Norte (UFRN).
} 
Essa "invasão" da Economia produziu impactos nada desprezíveis na Sociologia. Um dos seus desdobramentos mais perceptíveis foi a ascensão de perspectivas analíticas que incorporavam pressupostos muito próximos daqueles do campo econômico "invasor", especialmente as linhas mestras do empreendimento teórico da escolha racional. Rapidamente, o individualismo metodológico e a teoria dos jogos deixaram de ser abordagens marginais ou exóticas para se tornarem referenciais atrativos para toda uma geração de jovens e inquietos pesquisadores nas ciências sociais, de há muito insatisfeitos com modelos explicativos identificados por Jon Elster como expressões matizadas da explicação funcionalista dos fenômenos sociais. ${ }^{1}$

É nesse cenário que são lançados os trabalhos de um conjunto de pesquisadores que, alicerçados numa re-leitura de clássicos das ciências sociais como Max Weber e Simmel e numa original releitura da principal obra de Karl Polanyi, A grande transformação, propõemse a investigar tanto os processos específicos de institucionalização do mercado quanto os contornos assumidos, em realidades concretas, por dimensões tomadas como dados de realidade na análise econômica tradicional, tais como confiança, informação e escolha, dentre outras. Uma das primeiras aplicações dos princípios teórico-metodológicos que passariam a identificar a Nova Sociologia Econômica (a partir de agora, NSE) encontra-se no trabalho de Viviana Zelizer a respeito da construção social do mercado de seguro nos EUA. Zelizer (1983), seguindo de perto uma perspectiva analítica apresentada por Pierre Bourdieu no seu trabalho etnográfico entre os Kabilas, ${ }^{2}$ apontou a desnaturalização da entronização da morte como elemento a ser negociado no mercado através do seguro de vida.

Se a pesquisa de Zelizer é uma referência concreta na análise da construção social do mercado, constituindo-se numa contraposição empiricamente apoiada da idéia de autonomização do mercado perante a vida social, a resposta teoricamente mais significativa aos modelos da escolha racional viria de um agora já clássico artigo de Mark Granovetter publicado pelo American Journal of Sociology, em 1985. Granovetter, apoiando-se em referências a Max Weber e numa re- 
leitura da noção de submersão (embeddedness) do econômico pelo social propõe uma trilha de investigação sociológica da vida econômica em que o foco da análise se desloca da ação individual para as estruturas sociais, entendendo estas como um resultado contingente das interações entre indivíduos e organizações portadores de posições e lugares de poder distintos. Essas estruturas são produtos e, ao mesmo tempo, delimitadoras das ações desenvolvidas pelos atores.

Esses estudos abriram caminho para um conjunto de análises que, dialogando criticamente com economistas interessados na abordagem do papel das instituições na vida econômica (especialmente a chamada "nova Economia institucional", expressa nos trabalhos de Olivier Williamson), construíram, já no início da década de 90, um excitante "novo movimento teórico"3 na Sociologia. Articulando-se com perspectivas analíticas paralelas (como a análise de rede, os estudos culturais e o neo-institucionalismo), esse novo movimento teórico tem se traduzido não apenas numa maior sofisticação da análise sociológica da vida econômica, permitindo uma re-incorporação dos clássicos ao "cotidiano" da disciplina, numa trilha muito próxima daquela apresentada pela perspectiva "pós-positivista" de ciência social (Alexander, 1999, p. 31), mas também tem possibilitado o desenvolvimento de pesquisas originais e metodologicamente rigorosas que são uma resposta prática ao imperialismo disciplinar da Economia.

Neste artigo, busco traçar um panorama do rico universo desse campo da análise sociológica. O objetivo é o de apontar as múltiplas possibilidades de investigação sociológica potencializadas pela NSE e apresentar como essa perspectiva analítica articula-se com outras iniciativas de ponta nas ciências sociais contemporâneas. Algumas questões norteiam essa incursão: o que há de realmente novo nessa Sociologia Econômica? Quais os pontos de contato e quais as rupturas entre a NSE e a análise econômica tradicional? A minha expectativa é que o texto possa servir de um guia inicial sobre esse promissor filão de abordagem sociológica, suscitando o interesse do leitor para um contato mais aprofundado com os temas e a literatura aqui comentados. 


\section{Em busca da novidade, o encontro com os clássicos}

Em uma elucidativa entrevista, em que apontava os pressupostos teóricos de seu projeto teórico para a Economia, Gary Backer ajudou a criar uma certa confusão sobre o que seria a Sociologia Econômica. Reconstituindo o seu trajeto intelectual, Backer (1990) afirmou que praticava uma "Sociologia Econômica" ao aplicar ao estudo de fenômenos sociais os instrumentais teóricos e metodológicos de há muito hegemônicos na Economia. Na realidade, a obra de Backer é tomada como uma referência crítica pelos principais teóricos da NSE, na elaboração de uma recusa aos modelos da escolha racional. No geral, a NSE apresenta-se como uma resposta explícita à obra do conhecido prêmio Nobel de Economia.

Se deixarmos de lado a preocupação em qualificá-la como "nova", o que vem a ser uma Sociologia Econômica? Neil Smelser e Richard Swedberg argumentam que o termo é a melhor tradução para a aplicação da perspectiva sociológica à análise da vida econômica apresentada por Max Weber como sozialökonomik (1994, p. 20). De forma mais elaborada, a Sociologia Econômica seria "a aplicação das estruturas de referência, variáveis e modelos explicativos da Sociologia ao vasto campo de atividades ligadas à produção, distribuição, troca e consumo de bens e serviços escassos" (Smelser \& Swedberg, 1994, p. 3).

Antes de se dedicarem a apontar os elementos de novidade na Sociologia Econômica emergente na década de 80 (e que justificariam a junção da palavra "nova"), Smelser \& Swedberg explicitam, didaticamente, as diferenças teóricas entre a abordagem proposta pelo paradigma dominante na Economia e aquela que é desenvolvida a partir do horizonte epistemológico da Sociologia Econômica. Para tornar mais clara a exposição dos organizadores do cada vez mais citado Handbook of Economic Sociology, reproduzo, sem modificações substanciais, uma tabela por eles apresentada (Tabela 1). 


\section{Tabela 1 - A Sociologia Econômica e o mainstream econômico - uma comparação}

\begin{tabular}{|c|c|c|}
\hline & Sociologia econômica & Mainstream econômico \\
\hline Conceito de ator & $\begin{array}{l}\text { O ator é influenciado por } \\
\text { outros atores e integra grupos } \\
\text { e sociedades. }\end{array}$ & $\begin{array}{l}\text { O ator não é influenciado } \\
\text { por outros atores } \\
\text { ("individualis mo" } \\
\text { metodológico). }\end{array}$ \\
\hline Ação econômica & $\begin{array}{l}\text { Diferentes tipos de ação } \\
\text { econômica são mobilizados } \\
\text { pelos atores, incluindo a ação } \\
\text { racional; a racionalidade é } \\
\text { uma variável. }\end{array}$ & $\begin{array}{l}\text { Todos as ações } \\
\text { econômicas são apreen- } \\
\text { didas como sendo } \\
\text { racionais; a racionalidade } \\
\text { como um pressuposto. }\end{array}$ \\
\hline $\begin{array}{l}\text { Constrangimentos } \\
\text { sobre a Ação }\end{array}$ & $\begin{array}{l}\text { As ações econômicas são } \\
\text { constrangidas pela escassez de } \\
\text { recursos, pela estrutura social } \\
\text { e pela atribuição de sentidos. }\end{array}$ & $\begin{array}{l}\text { As ações econômicas são } \\
\text { constrangidas pelas } \\
\text { preferências e pela } \\
\text { escassez de recursos, } \\
\text { incluindo a tecnologia. }\end{array}$ \\
\hline $\begin{array}{l}\text { Relação Economia/ } \\
\text { sociedade }\end{array}$ & $\begin{array}{l}\text { A Economia é apreendida } \\
\text { como uma parte da sociedade; } \\
\text { a sociedade é sempre a } \\
\text { referência básica. }\end{array}$ & $\begin{array}{l}\text { O mercado e a Economia } \\
\text { são as referências } \\
\text { básicas; sociedade é } \\
\text { tomada como um } \\
\text { "dado". }\end{array}$ \\
\hline $\begin{array}{l}\text { Objetivo do método } \\
\text { de análise usado }\end{array}$ & $\begin{array}{l}\text { Descrição e explicação; } \\
\text { raramente predição. }\end{array}$ & $\begin{array}{l}\text { Predição e explicação; } \\
\text { raramente descrição. }\end{array}$ \\
\hline Métodos usados & $\begin{array}{l}\text { Os mais diferentes métodos } \\
\text { são usados, incluindo o } \\
\text { histórico e o comparativo. }\end{array}$ & $\begin{array}{l}\text { Método formal, espe- } \\
\text { cialmente modelos mate- } \\
\text { maticamente construí- } \\
\text { dos. }\end{array}$ \\
\hline Tradição intelectual & $\begin{array}{l}\text { Marx-Weber-Durkheim } \\
\text { - Polanyi-Parsons/Smelser; os } \\
\text { clássicos são constantemente } \\
\text { re-interpretados e tomados } \\
\text { como referências. }\end{array}$ & $\begin{array}{l}\text { Smith - Ricardo - Mill - } \\
\text { Marsh a } 11-\text { Ke y n e s- } \\
\text { Samuelson; os clássicos } \\
\text { pertencem ao passado; }\end{array}$ \\
\hline
\end{tabular}

Fonte: Smelser \& Sweberg, 1994, p. 4. 
Esse exercício comparativo reforça a filiação teórica da Sociologia Econômica com as obras weberiana e parsoniana. As condições sob as quais a racionalidade econômica torna-se possível passa a ser um objeto de investigação, ao invés do pressuposto. Como conseqüência, a análise sociológica dedica-se muito mais fortemente à apreensão do poder presente nas transações econômicas. Para o desenvolvimento dessa linha de investigação sociológica da vida econômica, a obra de Max Weber é a referência primeira, Especialmente o primeiro capítulo de Economia e Sociedade. Ainda no que diz respeito à racionalidade, a elaboração parsoniana da racionalidade como um sistema de normas associado com o processo de desenvolvimento da sociedade ocidental ${ }^{4}$ é, a partir dos exercícios analíticos empreendidos pela Sociologia Econômica, descolado de seu viés etnocêntrico e tornado um referente importante na crítica à idéia da racionalidade como um elemento psicológico universal.

Assim, Weber e Parsons fornecem as bases para um (re)pensar sobre a idéia de racionalidade e, dessa forma, contribuem para que, no momento mesmo da implosão dos modelos macro-estruturais na análise sociológica, a tradicional "Sociologia Econômica" pudesse se renovar, acompanhando o "novo movimento teórico" (Alexander, 1987) que ocorria de forma mais ampla no campo da Sociologia. E isso foi possível porque, a partir da apropriação desses autores clássicos, pode-se realizar uma análise da vida econômica (e, mais concretamente, a investigação pontual de mercados específicos), na qual os micro-fundamentos da ação não eram secundarizados em relação à lógica mais "geral" de estruturas e "entidades", como o Estado ou a Classe Social.

No que diz respeito à análise específica da construção do mercado, a novidade da Sociologia Econômica dos anos 80 está no fato de ter resgatado a obra de Karl Polanyi (1886-1964). Embora empobreça em demasia um autor capaz de produzir uma obra como $A$ grande transformação, pode-se propor que a contribuição primordial desse pensador tenha sido a superação do naturalismo histórico na apreensão da gênese do sistema de mercado. Referenciado nesse horizonte teórico e político, Polanyi assumiu uma posição 
substancialista (em oposição à formalista) na investigação da vida econômica. Essa compreensão se traduziu na noção de que os fenômenos econômicos encontram-se submersos (embeddedness) pelo todo social do qual fazem parte. Por isso, afirmará Polanyi ([1949] 1980) que "a idéia de um mercado auto-regulável” não passa de uma "rematada utopia" (p. 23).

Rejeitando tanto a defesa de uma autonomização do econômico em relação às demais esferas da vida social quanto a possibilidade de existência duradoura do mercado auto-regulável, Polanyi abriu o caminho teórico para a afirmação da idéia de uma inseparabilidade entre o econômico e o social. No que diz respeito ao mercado, e esse foi um dos mais importantes aportes para os trabalhos desenvolvidos por Zelizer e Granovetter, esse posicionamento levou Polanyi a considerar como elementos indispensáveis para compreender a construção do mercado, as regras, as leis, os sentidos, as normas e as paixões.

O conceito de embeddedness foi desenvolvido e reformulado por Mark Granovetter em um artigo que pode ser considerado, hoje, uma das expressões principais da NSE. Em Granovetter (1985), embeddednes expressa um ação econômica que se desenvolve dentro de uma rede de relações sociais, a partir da qual constitui-se a estrutura social. Paul Di Maggio, sociólogo mais devotado à análise das formas culturais, afirmará, alguns anos depois, que a ação econômica não está submersa (embedded) apenas na estrutura social, mas também na cultura (1990).

Um outro importante aporte na constituição da Nova Sociologia Econômica foi o seu conflituoso, mas frutífero, relacionamento com a análise institucionalista, que então começava a se consolidar no campo da disciplina econômica. A problematização do peso e do processo mesmo de construção social das instituições foi o terreno comum de disputa entre essas duas abordagens. No tópico a seguir, detalharei um pouco sobre esse outro filão teórico do qual se nutre a NSE. 


\section{Instituições e mercado: o terreno de análise e disputa entre a NSE e a Nova Economia Institucional (NEI)}

A análise institucionalista ganhou força na disciplina econômica, sendo um dos principais aríetes do imperialismo disciplinar praticado pela Economia em relação às Ciências Sociais. As elaborações e referenciais teórico-metodológicos mobilizados por essa abordagem têm influenciado fortemente um conjunto amplo de pesquisadores tanto na Sociologia quanto na ciência política. Por análise institucionalista, refiro-me ao que vem sendo denominado, no debate acadêmico, de Nova Economia Institucional (NEI) e que têm como nomes mais representativos Oliver Williamson e Douglas North.

Os autores acima mencionados, mesmo assumindo muitos dos pressupostos da "escolha racional", fazem parte, mesmo que indiretamente, de uma tradição de investigação econômica responsável pela mais poderosa crítica não-marxista à Economia política marginalista. Refiro-me ao "velho" institucionalismo americano das primeiras décadas do século e que teve em Thostein Bunde Veblen um de seus teóricos mais representativos. Esse institucionalismo elaborou uma contundente crítica ao hedonismo subjacente às análises do mainstream econômico de seu tempo, tendo como ponto de apoio uma investigação sobre as instituições do capitalismo ocidental (particularmente, norte-americano). Rejeitando o naturalismo da Economia ortodoxa, os "velhos institucionalistas" desenvolveram a proposição de que os arranjos sociais são passíveis de modificação pela ação coletiva. Em outras palavras, entendiam que a ordem econômica e social era criada e mantida por ajustamentos institucionais voluntários que emergiam apesar de, e/ou contra, a "ordem espontânea do mercado".

Pelo impacto de sua obra no conjunto do pensamento social contemporâneo, vale a pena, antes de voltar às relações entre Sociologia Econômica, NEI e velho institucionalismo, fazer uma referência mais detalhada a respeito de Veblen. Tendo como ponto de partida uma criativa apropriação de Princípios de Psicologia, de William James, Veblen empreendeu uma vigorosa crítica à perspectiva psicológica da Economia marginalista. Ao mesmo tempo, e por isso, 
é considerado o "pai" da análise institucionalista, Veblen assinalou a importância da cultura para a compreensão da vida econômica.

$\mathrm{Na}$ abordagem da vida econômica proposta por Veblen, aponta um comentador de sua obra, "os esquemas culturais no quais se insere a ação do homem são o produto de sua herança, de sua experiência passada, traduzidas por intermédio de tradições e convenções". Assim, a ação econômica na apreensão de Veblen não poderia ser analisada desvinculada do contexto cultural com o qual forma um "complexo orgânico de hábitos de pensamento" (Renaut, 1992, p. 181).

Em que esse tipo de elaboração aproxima-se da NEI e da NSE? No terreno comum de apreensão dos processos de institucionalização da vida social. No entanto, como se verá logo a seguir, há uma grande distância entre a aproximação "culturalista" dos primeiros institucionalistas e a abordagem mais ou menos alicerçada no individualismo metodológico da NEI. Uma maior incursão na vasta literatura sobre instituições, mercado e vida econômica exige, entretanto, uma demarcação inicial: do que exatamente estamos falando quando nos referimos a instituições? Para North (1990), as principais características das instituições são delimitar escolhas e possur mecanismos de implementação de decisões. As instituições regulariam o "jogo", possibilitando a identificação dos "jogadores" e, dessa forma, reduziriam os comportamentos imprevisíveis. Essa explicação dá um papel funcional às instituições: elas contribuiriam para diminuir os riscos dos contratos ou, conforme toda uma tradição analítica, os "custos de transação".

Parte da análise desenvolvida por Williamson dará à sua obra o caráter de uma verdadeira "teoria dos custos de transação". Em The economic institutions of Capitalism, publicado em 1985, ele deixa claro o que orienta o seu projeto de análise: "contrariamente às velhas concepções - nas quais as instituições econômicas do capitalismo são apreendidas pela referência ao interesse de classe, tecnologia ou monopólio de poder - a teoria dos custos de transação sustenta que essas instituições têm como principal propósito e efeito diminuir os custos de transação" (Williamson, 1985, p. 1). Em uma obra publicada dez anos antes, Williamson (1975) deixava claro que entendia transação como sendo uma relação bilateral. Os custos de transação 
eram então percebidos como consequiências da informação incompleta e da habilidade cognitiva limitada ou racionalidade limitada (bounded rationality).

O mais importante a ser ressaltado é o fato de que, para Williamson e boa parte dos teóricos da NEI, as instituições são apreendidas como complementos necessários ao funcionamento "perfeito" do mercado. Dessa forma, a instituição é tomada quase como um sinônimo de constrangimento e ganha o estatuto de algo oposto ao "mercado" (espaço da livre troca). Se essa perspectiva analítica não rompe, pelo contrário, reafirma o mainstream da análise econômica atual, qual a sua importância para uma abordagem sociológica renovada da vida econômica como aquela presente na NSE?

Foi no confronto teórico com as elaborações mais proeminentes da NEI que emergiram os trabalhos hoje identificados como fundadores da abordagem da NSE. Tanto do ponto de vista da prática da pesquisa social sobre a vida econômica, como é o caso das análises empreendidas por Zelizer (1983 e 1989), ou nas elaborações marcadamente teóricas. Neste último caso, além do já citado artigo de Granovetter (1985), devo destacar as respostas dadas a alguns dos principais argumentos mobilizados por Williamson. Esse o caso, por exemplo, da análise feita por Charles Perrow. Diante da proposição de que a "eficiência é o principal e o único fator sistemático responsável pelas mudanças organizacionais que têm ocorrido" (Williamson, 1986, p. 255), Perrow (1986) responde o quanto esse tipo de abordagem desconsidera algo que seria fundamental para apreender a dinâmica institucional: a dimensão do poder tanto interno a cada instituição e organização quanto aquele que permeia as relações interinstitucionais. Perrow (1986, p. 247) argumenta ainda em defesa da idéia de que as motivações que delimitam os contornos das instituições e organizações (como firmas, por exemplo) estão inseridas num complexo conjunto de arranjos sociais. A motivação para diminuir os "custos de transação" pode até ser tomada como uma variável explicativa para a existência e/ou funcionamento das instituições, mas a sua influência seria modesta na conformação dos arranjos institucionais. 
Igualmente significativa foi a crítica elaborada por Neil Fligstein. Seguindo um caminho paralelo ao de Perow, e tendo por base uma pesquisa de campo realizada junto às principais empresas norte-americanas, Fligstein (1985) demonstrou que, ao contrário do que apontara Williamson, as mudanças organizacionais longe de representarem uma resposta aos objetivos de "eficiência" e diminuição de "custos" traduzem, muitas vezes, os cenários organizacionais resultantes de ações que se relacionam, primordialmente, com as posições dos atores no interior da organização ou instituição.

Fligstein (2001, on line), nos últimos tempos, tem complexificado a sua análise das mudanças organizacionais, estreitando os laços entre a NSE e o "neo-institucionalismo", tendo como eixo articulador de sua análise o conceito de "habilidade social". Essa habilidade seria a capacidade de um ator em provocar o engajamento de outro(s) em processos de cooperação. A inspiração vem do interacionismo simbólico, particularmente de Mead (1939) e Goffman ([1959] 1985).

Se esse conjunto de leituras e re-interpretações dos temas expostos por Williamson se tornaram elementos constitutivos da NSE, isso só foi possível porque, como reconheceram recentemente Swedberg \& Granovetter (2001), havia um projeto intelectual que animava esse debate: a resposta ao "imperialismo disciplinar". No início da década de 90, quando as paisagens políticas e sociais ainda alimentavam as elaborações econômicas neoclássicas, era "crucial abrir o debate acadêmico a respeito da Economia para incluir um perspectiva genuinamente social e que levasse em conta as interações das pessoas reais" (2001, p. 1).

O rico debate realizado no período ainda serve de referência e balizamento para muito do que ocorre na análise da vida econômica no universo acadêmico norte-americano e, como veremos adiante, tem um impacto cada vez maior em outros países, especialmente na Europa. Por isso mesmo, e para tornar mais acessível o mapeamento dessa produção, apresentamos a Tabela 2, baseada livremente na análise empreendida por Sweldberg \& Granovetter (2001). 


\section{Tabela 2 - Instituições e vida econômica na Sociologia e Economia nos anos 90}

\begin{tabular}{|c|c|c|}
\hline Abordagem & Proposição central & Autores principais \\
\hline $\begin{array}{l}\text { Nova Sociologia } \\
\text { Econômica }\end{array}$ & $\begin{array}{l}\text { A Sociologia oferece, através } \\
\text { de conceitos como o do } \\
\text { embeddedness e do rico } \\
\text { arsenal teórico-metodológico } \\
\text { dos clássicos, uma importante } \\
\text { base para a análise social dos } \\
\text { problemas econômicos. }\end{array}$ & $\begin{array}{l}\text { Mark Granovetter } \\
\text { Harrison C. White } \\
\text { Viviana Zelizer }\end{array}$ \\
\hline $\begin{array}{l}\text { Sociologia da } \\
\text { escolha racional }\end{array}$ & $\begin{array}{l}\text { A idéia central é a de que a } \\
\text { Sociologia precisa ser } \\
\text { reformada para incorporar a } \\
\text { perspectiva analítica da } \\
\text { escolha racional }\end{array}$ & $\begin{array}{l}\text { James Coleman } \\
\text { Victor Nee } \\
\text { Michael Hechter }\end{array}$ \\
\hline $\begin{array}{l}\text { Nova Economia } \\
\text { Institucional }\end{array}$ & $\begin{array}{l}\text { As instituições têm um papel } \\
\text { central na Economia e a } \\
\text { análise de seu funcionamento } \\
\text { e desempenho pode ser } \\
\text { melhor compreendido através } \\
\text { da utilização dos } \\
\text { instrumentais fornecidos pela } \\
\text { micro Economia e pela teoria } \\
\text { dos "custos de transação". }\end{array}$ & $\begin{array}{l}\text { Oliver Williamson } \\
\text { Douglas North }\end{array}$ \\
\hline $\begin{array}{l}\text { I m p e r i a l i s m o } \\
\text { econômico } \\
\text { (a análise de temas } \\
\text { sociológicos por } \\
\text { economistas) }\end{array}$ & $\begin{array}{l}\text { A micro Economia pode ser } \\
\text { usada não só para dar conta } \\
\text { da vida econômica, mas pode } \\
\text { ser usada como instrumental } \\
\text { analítico para fornecer } \\
\text { explicações para as mais } \\
\text { amplas dimensões da vida } \\
\text { social (incluindo preferência } \\
\text { político-partidária, crime, } \\
\text { religão, cultura e família). }\end{array}$ & \\
\hline
\end{tabular}

Não resta dúvidas de que o rico debate produzido pelas respostas à NEI e à invasão do campo disciplinar da Sociologia por economistas como Gary Backer é um dos marcos fundadores da NSE. Entretanto, o desenvolvimento da NSE seria impossível se não pudesse ter contado 
com as instigantes abordagens sociológicas conduzidas por Viviana Zelizer. Por isso mesmo vale a pena destacar um pouco mais o tipo de abordagem desenvolvido por essa socióloga, cuja obra causa impactos em campos tão diversos como na Sociologia da Criança e nos estudos jurídicos.

\section{A análise de Viviana Zelizer sobre o mercado de crianças: uma análise sociológica exemplar da NSE}

A análise empreendida por Zelizer (1987) sobre a constituição e evolução do mercado de crianças nos EUA no período de 1870 a 1930 tem sido tomada como umas das principais referências analíticas da NSE. Por isso mesmo, vale a pena uma apresentação, mesmo que panorâmica, desta original e provocativa investigação sociológica.

O mercado de crianças tem como vetor instituinte a demanda, existente na segunda metade do século XIX, nos EUA, por "crianças úteis" que pudessem trabalhar tanto em casa quanto nas atividades agrícolas. Nesse momento, surgem as "babás profissionais" e todo um conjunto de pequenos empreendimentos agenciadores de cuidados para bebês de mães solteiras e famílias pobres. Além de receberem um determinado pagamento (na maioria das vezes, das mães), esses novos profissionais tinham o direito, mais ou menos reconhecido socialmente, de que, quando a criança "cuidada" chegasse aos sete ou oito anos de idade, eles deteriam o passe de sua venda ao mercado de trabalho infantil. Tratava-se, aponta Zelizer (1987), de um mercado legitimado e tido como honesto e transparente. O Estado intervinha raramente e, na maioria das vezes, apenas para combater os "excessos" praticados pelas agências ou pelas famílias compradoras de crianças.

Nesse mercado, as crianças tinham o seu preço determinado pela idade e capacidade de trabalho. Tanto as crianças portadoras de deficiência quanto aquelas mais frágeis, cujos preços no mercado posteriormente não compensariam anos de investimento e "cuidados", eram muitas vezes descartadas e deixadas sob a responsabilidade das tristemente famosas instituições de caridade. A morte prematura era o seu destino. Do ponto de vista étnico, esse era um mercado "democrático": como a criança comprada destinava-se ao trabalho, 
era a sua capacidade de trabalho e não a cor que determinava o seu preço.

O projeto de investigação de Zelizer objetivou analisar o preço da criança quando a adoção (que, na verdade, era uma "compra") para o trabalho passa a ser condenada socialmente. Esse é o momento no qual a adoção de crianças passa a ter na afetividade e no tratamento "como um filho" os pilares de sua justificação. O mercado de crianças passa, então, por uma significativa transição: de mercado de força de trabalho infantil a mercado de seres destinados ao afeto dos seus compradores. As crianças não são mais valorizadas por serem "úteis" (para as atividades domésticas e os pesados trabalhos no campo), mas pelo que podem potencializar em termos de bem-estar emocional e afetividade para as famílias que irão adotá-las.

A situação é paradoxal: quando as crianças tornam-se "inúteis" (como força de trabalho), devido à pressão social (a luta contra o trabalho infantil mobilizara o movimento sindical desde as últimas décadas do século XIX) e o aparecimento de uma legislação trabalhista, o seu preço torna-se monetariamente elevado. Em uma apresentação sintética de seu trabalho, Zelizer expressa os condicionantes culturais dessa evolução no mercado de crianças:

As preferências dos parentes adotivos do século XX, em matéria de sexo e idade, traduzem a evolução cultural porque passou a adoção. Enquanto no primeiro período, o valor dado à criança útil realçava a preferência por crianças robustas e de mais idade, especialmente do sexo masculino; num segundo momento serão os bebês, particularmente do sexo feminino, que serão os alvos da procura do mercado de adoção. (Zelizer, 1992, p. 19).

O trabalho de Zelizer é, além de uma investigação sociológica original de um processo específico de construção social do mercado, também uma vigorosa denúncia das relações que estruturam um mercado cuja força e valores só tem crescido nos últimos anos. Funcionando numa área fronteiriça entre a legalidade e a ilegalidade, o mercado de crianças não tem tido a sua força e abrangência arrefecidos pelas denúncias em torno do "mercado negro" (relacionado com o tráfico de órgãos e a pedofilia). Muito pelo contrário: atuando na legalidade, o mercado de crianças continua a pleno vapor, embora transacionando com uma moeda específica (denominada "custo do 
processo", na qual o preço da criança é embutido no pagamento à maternidade e ao escritório de advogados). Na década de 90 do século passado, um bebê branco e de olhos azuis poderia alcançar o preço de U\$ 100 mil. As agências de adoção continuam funcionando, como nos velhos tempos do mercado de trabalho infantil, e, ainda nas décadas de 40 e 50, conforme Zelizer (1992), o faturamento anual de uma dessas agências poderia alcançar a cifra de um milhão de dólares.

Mas a originalidade e a denúncia não garantiriam a relevância da análise empreendida por Zelizer. O mais importante, e o que define o seu trabalho como fundador da NSE, é o fato de ter apreendido a evolução desse singular mercado tomando a cultura e a instituição de moedas específicas como pilares de sua explicação sociológica. Assim, Zelizer toma dois valores culturais fortes na primeira metade do século XX na sociedade norte-americana como vetores culturais da mutação do mercado de crianças: a) a socialização da teoria da influência do meio sobre o indivíduo; b) a condenação do trabalho infantil; e, c) a valorização afetiva da criança.

Num momento histórico como o da década de 30, em que figuras do mundo artísticos eram incentivadas a fazer adoções, a criança passa a ser representada socialmente "sem preço". Ironicamente, é exatamente nesse momento que o seu preço monetário explode. Essa apreensão autoriza Zelizer a uma refutação vigorosa da investida imperialista disciplinar da Economia:

Existe um grande mercado de crianças, mas ele não coincide com o modelo neoclássico de um mercado único, puramente instrumental, fora do alcance das perturbações sociais ou culturais. No caso das crianças, o mercado é alicerçado na definição das crianças que faz delas seres 'sem preços' e pelas transformações sociais e econômicas ocorridas no seio da família. (Zelizer, 1992, p. 22).

\section{Pontes e trilhas: os desdobramentos da NSE nas ciências sociais}

Talvez pudéssemos apreender a NSE como um campo centrífugo e centrípeto ao mesmo tempo. Para a sua órbita são atraídas análises e especulações oriundas das mais distintas práticas de saber e tradições 
discursivas, mas, ao mesmo tempo, das elaborações produzidas no seu interior emergem novas e autônomas áreas de investigação nas ciências sociais. Esse é o caso do que se pode identificar como Sociologia da firma, articulada em torno das trilhas de pesquisa abertas pelas elaborações de Neil Fligstein anteriormente comentadas. Além disso, a interlocução da NSE com campos temáticos, como aquele dos estudos culturais (cultural studies), tem avançado na medida em que aumenta, no interior das ciências sociais, o interesse pelas últimas elaborações do conceito de embeddedness que, na leitura de Paul Di Maggio (1997), por exemplo, desloca-se das estruturas sociais e adentra o terreno da cultura.

O trabalho desenvolvido por Di Maggio forneceu importantes contribuições para uma proposta de investigação sociológica que, mesmo tendo construído uma trajetória paralela, tem muitos pontos de contato com a NSE. Refiro-me à network analysis. Muito embora a utilização abusiva do conceito de "rede" nos últimos anos tenha contribuído para ofuscar os ganhos teóricos e epistemológicos impulsionados pela abordagem sociológica proposta pela network analysis, não resta dúvida que, em territórios específicos da NSE, como a análise sociológica do mercado financeiro, a articulação entre esses duas linhas de investigação social tem aclarado algumas da mais importantes dimensões da vida econômica contemporânea.

O conceito de rede assumido por essa perspectiva analítica tem fortes vinculações com aquele de embeddedness que, como vimos, foi central no desenvolvimento da NSE. Vejamos, a esse respeito, a definição feita por um sociólogo brasileiro que tem se aproximado da network analysis a partir do campo disciplinar da ciência política: "entende-se por rede o campo, presente em determinado momento, estruturado por vínculos entre os indivíduos, grupos e organizações construídos ao longo do tempo" (Marques, 1999, p. 41).

Essa apreensão, articulada ao universo conceitual acumulado pela NSE, tem potencializado o desenvolvimento de um conjunto de análises sociológicas identificado apressadamente como "Sociologia da firma". Essa Sociologia, cujas trilhas foram inicialmente abertas com as elaborações de Fligenstein, tem sido, nos últimos anos, a base para a elaboração de pesquisas sobre as redes sociais subjacentes aos arranjos intra e inter-empresas, especialmente transnacionais. Também 
têm saído desse campo as análise sociológicas sobre os atores envolvidos na construção social dos mercados financeiros. Em artigo recente, Brian Uzzi (1999) apresenta o "estado da arte" dessa sociologia.

Os desdobramentos teóricos da NSE dirigem-se a outras importantes dimensões da vida econômica. Esse é o caso dos estudos sobre a relação entre criação e/ou circulação de moedas e transações pessoais.

A idéia de que as relações impessoais e anônimas são os únicos meios através dos quais as moedas circulam é fortemente enraizada nas ciências sociais. Não raro, aparece como um pressuposto de análises sociológicas sobre processos de emergência de relações de mercado. Uma das grandes conquistas teóricas das investigações desenvolvidas por Viviana Zelizer foi a de ter demonstrado que as moedas também se movem nas relações aparentemente mais distanciadas da lógica mercantil, dentre elas os relacionamentos pessoais (Zelizer, 1995). No nosso vocabulário cotidiano essas moedas são identificados como "presente", "recompensa" ou "indenização".

O trabalho de Zelizer forneceu importantes pontos de apoio para uma análise sociológica das "transações íntimas" e deu à análise sociológica da vida econômica um rigor analítico saudado por autores como Pierre Bourdieu. ${ }^{6}$ Do ponto de vista da pesquisa social, essa obra serve de referência para um conjunto de trabalhos que buscam se apropriar da análise da vida econômica a partir de uma ótica feminista (ou das relações de gênero). Uma boa parte dessa produção pode ser encontrada na revista Feminist Economics. Investigações sociológicas sobre as percepções de pagamento nos chamados "trabalhos sociais" (especialmente aqueles dedicados ao cuidado de idosos e crianças) também são reforçadas pela incorporação das chaves de leitura fornecidas pela obra de Zelizer.

Pesquisadoras feministas dedicadas à análise econômica têm tomado as assunções da NSE presentes no trabalho de Zelizer para assestar um ataque ao viés de gênero presente na interpretação da ação econômica fornecida pelos neoclássicos e seus modernos cultores. A crítica tem apontado para o fato de que o indivíduo maximizador de seus interesses pessoais idealizado pela Economia neoclássica pode 
ser criticado não apenas pela fragilidade dos seus pilares filosóficos e sociológicos, mas também pelo seu forte viés de gênero (cf. Nelson, 1993, 1996) Isso porque, longe de significar um rigor analítico, esse pressuposto tem funcionado para ocultar uma percepção da vida econômica que é encaixada nos esquemas de interpretação de mundo alimentados pela dominação masculina.

A aproximação entre a teoria feminista e a NSE tem se traduzido numa devastadora crítica ao androcentrismo (percepção da realidade a partir do olhar masculino) presente não apenas na Economia, mas também, e principalmente, na Sociologia. Para Folbre \& Nelson (2000, p. 130), essa perspectiva fica muito clara quando alguns economistas, como Gary Backer, analisam a vida familiar e o comportamento sexual. Eles apreendem essas dimensões da vida em sociedade como sendo produtos de escolhas e trocas. O fato de a mulher dedicar-se ao trabalho doméstico, por exemplo, é apreendido pelos economistas neoclássicos como uma consequiência da elevação de custos do trabalho doméstico assalariado. Tudo se passa como se nenhuma mudança de ordem qualitativa necessitasse ser explicada. Não raro, a abordagem dominante na análise econômica assume como pressupostos elaborações que tratam o ser masculino como racional e com maior interesse na "realização pessoal", ao passo que a mulher é assumida como estando mais vinculada ao "lugar" e às emoções e, portanto, mais motivada para, nos re-arranjos domésticos impulsionados por mudanças produzidas no mercado, dedicar-se às atividades de cuidado das crianças e da casa.

Se, no que diz respeito à análise do que poderíamos denominar como transações íntimas, a NSE articulada com a teoria feminista potencializa a crítica aos postulados da Economia neoclássica e às análises sociológicas baseadas no individualismo metodológico, na sua ponte com os estudos de migração, referenciando-se no conceito de rede social fornecido pela network analysis, contribui para tornar mais cultural a análise dos processos migratórios. Isso porque, no que diz respeito à Sociologia da migração (especialmente aquela praticada nos EUA), alguns dos pressupostos norteadores do inidvidualismo metodológico estiveram na base do seu desenvolvimento. Também no que se refere à investigação sociológica dos processos migratórios, a incorporação da NSE teve o sentido de, potencializando a 
instrumentalização dos conceitos de embeddednes e rede social, fornecer elementos para uma crítica de assunções como a de que a decisão de emigrar é o resultado do cálculo racional de um ator.

A este respeito, vale lembrar que pesquisadores da área, como Michael Todaro (1986), adotavam como ponto de partida de suas pesquisas a idéia de que a decisão de migrar correspondia a um cálculo no qual entravam as possibilidades de ganho (empregos e salários) e os riscos (deportação). A resposta dada por autores como Douglas Massey e Alejandro Portes, dentre outros, foi a de que, mesmo quando os atores agem isoladamente eles não o fazem desconectados de uma densa rede de relações. Assim, a análise das redes de migração (sua estruturação, relações de poder, capacidade de mobilização de recursos, etc.) deveria ocupar um papel destacado na interpretação dos fenômenos migratórios, especialmente das grandes migrações internacionais que se destinam aos EUA. Essas redes de migração estruturar-se-iam em densas relações de reciprocidade e apoios familiares. Ligando os lugares de origem àqueles de destino, as redes de migração processam informações e são campos articulados com base na confiança. Para utilizar aqui uma linguagem próxima daquela mobilizada pela NSE nas suas narrativas de dimensões da vida econômica, a rede de migração encontra-se sempre submersa em estruturas sociais e delimitada pelo universo cultural que modula os esquemas de percepção dos migrantes. Esse o caminho apontado por Portes \& Sensenbrenner (1993).

A interação entre a NSE e os estudos de migração tem produzido uma redefinição positiva da análise sociológica da mobilidade populacional no início do século XXI. Essa situação tem se manifestado em três importantes direções: a) a incorporação da preocupação com a mobilização de recursos (econômicos, políticos e culturais) pelas redes de migração tem levado à produção de pesquisas pontuais sobre migração e capital social; b) a apreensão da rede de migração como econômica e socialmente submersa tem levado a uma maior sensibilidade para com os esquemas de interpretação e modelos culturais das pessoas envolvidos com a migração; c) a preocupação em analisar as estruturas de poder tanto produzidas pelas redes quanto aquelas com as quais se encontram envolvidas tem aberto espaço para uma maior sensibilidade em torno da relações de gênero presentes no 
processo migratório (as construções sociais dos papéis masculinos e femininos informam os esquemas de interpretação mobilizados pelas pessoas que participam das redes sociais de migração).

Esse tipo de abordagem alargou os espaços de diálogo entre a NSE e o projeto de Sociologia proposto por Pierre Bourdieu. Em seus últimos escritos, especialmente naqueles dedicados a uma revisão dos ganhos teóricos alcançados com o seu trabalho etnográfico na Argélia, Bourdieu não apenas deixou importantes pistas para o desenvolvimento de uma Sociologia reflexiva da migração (Bourdieu \& Wacquant, 2000) quanto explicitou os laços (e distanciamentos) dessa Sociologia com NSE, referindo-se explicitamente a Granovetter e Zelizer (2001).

A grande quantidade de material disponível na Internet sobre a NSE é uma expressão do interesse suscitado por esse inovador conjunto de abordagens sociológicas da vida econômica. Destaco aqui a excelente revista Economic Sociology European Eletronic Newsletter, que conta com Richard Swedberg como membro de seu comitê editorial, e é disponibilizada através da página http:// www.siswo.uva.nl/. Também merece referência a página do Center for Culture, Organization, and Politics, que disponibiliza na sua página http://ist-socrates.berkeley.edu/ iir/culture/, working papers de autores de destaque da NSE. Finalmente, há uma série de ensaios de autores de destaque da NSE disponíveis no site http:// www.gsm.uci.edu/econsoc/HomeFrames.htm, mantido pela American Sociological Association.

\section{Conclusão}

Os desdobramentos teóricos e as conquistas advindas de muitas das incursões ousadas no estudo de dimensões da vida econômica que até então eram naturalizadas pelas ciências sociais fez com que a NSE fosse se constituindo em algo como um espaço de saberes nômades. Isto é, de saberes que reagindo às investidas do imperialismo disciplinar dos economistas não se deixam encurralar pelo "paroquialismo disciplinar" (Sawyer, 2000, on line). Assim, a NSE não deixa de dialogar e estabelecer pontes com as discussões e problemas tradicionalmente abordados pelos economistas, mas, nem 
por isso, deixa de fincar raízes em direção às temáticas centrais do projeto da Sociologia enquanto disciplina acadêmica. Sem se render aos enquadramentos dos rótulos, a NSE pode ser apreendida tanto como um dos melhores exemplos de um projeto coletivo de investigação da realidade social contemporânea alicerçado numa apropriação crítica e criativa dos clássicos da jovem ciência da sociedade quanto como numa expressão de uma prática de desenvolvimento teórico que, sem se render aos apelos da fluidez e pouco rigor das propostas interdisciplinares, constrói-se de forma aberta e plural, potencializando o que de melhor a Sociologia tem a oferecer enquanto movimento de autocompreensão da modernidade.

\section{Notas:}

1 Ver Elster (1985 e 1994).

2 Zelizer toma como referência o trabalho feito conjuntamente por Bourdieu \& Sayad (1964).

3 Sobre a emergência de novos movimentos teóricos na Sociologia nesse momento, ver Alexander (1987).

4 Ver a respeito, Parsons ([1940] 1944).

5 "Transações íntimas" é o título provisório de um trabalho ainda inédito de Zelizer, dedicado à análise das moedas e pagamentos na vida doméstica. Agradeço a autora pela gentileza em me permitir acesso a esse texto.

6 Ver a respeito, Bourdieu (2000).

Abstract: The New Economic Sociology is the most promising reaction of sociology against the "economic imperialism" that happened in the field since the 80 's. In this article, we draw an overview of this rich research field of the contemporary social theory.

Key-words: Sociological theory, Economic Sociology, institutions and markets

Résumé: Dans le champ de la sociologie, la Nouvelle Sociologie Économique est la plus prometteuse réaction face à l'investissement 
de l'«impérialisme disciplinaire» de l'économie dans les années 80 . Dans cet article, on essaye de tracer un panorama de ce riche champ d'investigation sociologique contemporain.

Mots-clés: Théorie sociologique; Sociologie Économique; institutions et marchés.

\section{Referências bibliográficas:}

ALEXANDER, Jeffrey C. O novo movimento teórico. Revista Brasileira de Ciências Sociais, v. 2, n. 4, 1987.

A importância dos clássicos. In: GIDDENS, Anthony; TURNER, Jonathan (Orgs.). Teoria social hoje. São Paulo: Editora da UNEP, 1999.

BACKER, Gary. Interview. In: SWEDEBERG, Richard. Economics and Sociology: redefining their boudaries: conversations with Economists and Sociologists. Princeton: Princeton University Press, 1990. p. 2746.

BOURDIEU, Pierre. Making the economic habitus: Algerian workers revisited. Ethnography, v. 1, n. 1, p. 17-42, 2000.

BOURDIEU, Pierre; SAYAD, Abdelmalek. Le déracinement: la crise de l'agriculture traditionnelle en Algérie. Paris: Editions de Minuit, 1964.

BOURDIEU, Pierre; WACQUANT, Löic. The organic ethnologist of algerian. Ethnography, v. 1, n. 2,. p. 197-182, 2000.

DI MAGGIO, Paul. Cultural aspects of Economic organization and behavior. In: FRIEDLAND, R.; ROBERTSON, A. F. Beyond the market place: rethinking Economy and Society. New York: Aldine, 1990.

ELSTER, Jon. Making sense of Marx. Chicago: The University of Chicago Press, 1985.

. Um commento a Willliamson. Stato e Mercato, n. 40, 1994.

FLIGSTEIN, Neil. Social skill and theory of fields. Disponível em: http:// repositories.cdlib.org. Acesso em: dez. 2001.

FOLBRE, Nancy; NELSON, Julie A. For love or money - or both? Journal of Economic Perspectives, v. 14, n. 4, 2000.

GOFMAN, Erving. A representação do Eu na vida cotidiana. Petrópolis: Vozes, 1985. 
GRANOVETTER, Mark. Economic action and social structure: the problem of embeddedness. American Journal of Sociology, n. 90, 1985.

MARQUES, Eduardo C. Redes sociais e instituições na construção do Estado e da permeabilidade. Revista Brasileira de Ciências Sociais, v. 14, n. 41, 1999.

MASSEY, Douglas. Social structure, household strategies, and the cumulative causation of migration. Population Index, v. 1, n. 56, 1990.

NELSON, Julie A. The study of choice or the study of provisioning? gender and the definition of Economics. In: FERBER, Marianne A.; NELSON, Julie A. (Orgs.). Beyond economic man. Chicago: University of Chicago Press, 1993.

NELSON, Julie A. Feminism, objectivity and Economics. London: Routledge, 1996.

PARSONS, Talcott. Motivation of economic activities. In: Essays in Sociological Theory. New York: Oxford University Press, 1954.

POLANYI, Karl. A grande transformação. Rio de Janeiro: Campus, 1980.

PERROW, Charles. Complex organizations: a critical essay. New York: McGraw-Hill, 1986.

PORTES, Alejandro; SENSENBRENNER, Julia. Embeddedness and immigration: notes on the social determinants of economic action. American Journal of Sociology, n. 98, v. 6, 1993.

RENAULT, Michel. L'economie institutionaliste et la philosphie pragmatique: la nature humaine, les totalités et les valeurs. Economies et Société, n. 17, 1992.

SAWYER, Andrew. Long live postdisciplinary studies! Sociology and the curse of disciplinary parochialism/imperialism. Disponível em: $<\mathrm{http}: /$ /www.comp.lancaster.ac.uk/sociology/soc025as.html>. Acesso em: julho, 2000.

SWEDBERG, Richard; GRANOVETTER, Mark. Introduction to the Second Edition. In: GRANOVETTER, Mark; SWEDBERG, Richard (Orgs.). The Sociology of economic life. Boulder: Westview Press, 2001.

TODARO, Michael P. A theory of illegal international migration from developing countries. 1986. (Working Paper from the Center for Policy Studies, n. 126)

UZZI, Brian. Embeddedness in the making of financial capital: how social relations and networks benefit firms seeking financing? American Sociological Review, v. 64, n. 1, 1999. 
WILLIAMSON, Oliver E. Markets and hierarchies: analysis and antitrust implications. New York: Free Press, 1975.

. The economic institutions of capitalism. New York: Free Press, 1985.

ZELIZER, Viviana. Morals and markets: the development of life insurance in the United States. New Brunswick: Transations Publishers, 1983, 1983.

. Princing the priceless child: changing social value of children. New York: Basic Books, 1989, 1989.

. Repenser le marché. Actes de la Recherche em Sciences Sociales, n. 94, 1992. . The social meaning of money. New York: Basic Books, 1985. . Next steps in Economic Sociology. Disponível em: <www.gsm.uci.edu/econsoc/Zelizer.html>. Acesso em: dez. 2001. 